\title{
A fuzzy ANP application for prioritizing the productivity factors based on university employees' counterproductive behaviors
}

\author{
Zahra Alipour Darvishi*
}

Department of Management and Social Sciences, Islamic Azad University, Tehran North Branch Tehran, Iran

\begin{tabular}{|c|c|}
\hline C HRON I C L E & ABSTRACT \\
\hline $\begin{array}{l}\text { Article history: } \\
\text { Received January 4, } 2014 \\
\text { Accepted } 1 \text { June } 2014 \\
\text { Available online } \\
\text { June } 3 \text { 2014 } \\
\text { Keywords: } \\
\text { Fuzzy ANP } \\
\text { Human resource development } \\
\text { Counterproductive behavior }\end{array}$ & $\begin{array}{l}\text { Measuring the relative efficiency of employee plays essential role on the success of any } \\
\text { organization including universities. In this paper, we present a survey to detect and to prioritize } \\
\text { important factors influencing on the productivity of employees who work for one of Iranian } \\
\text { universities located in city of Tehran, Iran. The study also uses analytical network process to } \\
\text { prioritize the factors. Based on the results of our survey, we have categorized effective } \\
\text { productivity factors into three groups of research, educational and administration groups. In our } \\
\text { survey, coherence and unity with no dispersion of the employee's duties, systematic job rotation } \\
\text { and correct design communication job are among the most important factors influencing on } \\
\text { employees' productivity. }\end{array}$ \\
\hline
\end{tabular}

\section{Introduction}

Human resources are believed to be the primary source of having value added organizations. In fact, many organizations believe the human resources are the main reasons for having creative knowledge based business unit. There are literally many studies on learning more about what could influence on employee performance (Allameh et al., 2011; Bloom \& Reenen, 2011; Zheng \& Sun, 2011). OleyaeiMotlagh and Bonyadi-Naeini (2014), for instance, illustrated the intense of relationships between the human resources management indices and Six Sigma project implementation indices for some selected Iranian manufacturing firms. Divkolaii (2014) presented a study to determine various factors impacting productivity of human resources of Islamic Republic of Iran Broadcasting (IRIB) in province of Mazandaran, Iran. The study uses analytical hierarchy process (AHP) to rank 17 factors and determined that personal characteristics were the most important issues followed by management related factors and environmental factors. In terms of personal characteristics, job satisfaction played important role on human resources development. In terms of managerial factors, paying attention on

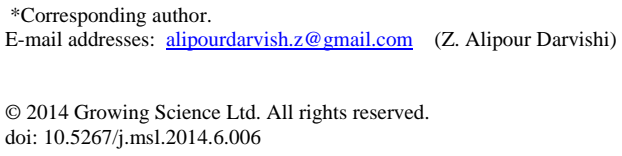


continuous job improvement by receiving appropriate training was the most important factor followed by welfare facilities for employees and using a system of reward/punishment in organization. Finally, in terms of environmental factors, occupational safety was number one priority followed by organizational rules and regulations.

\section{The proposed study}

In this paper, we present a survey to detect and to prioritize important factors influencing on the productivity of employees who work for one of Iranian universities located in city of Tehran, Iran. The study also uses analytical network process (ANP) to prioritize the factors. Based on the results of our survey, we have categorized effective productivity factors into three groups of research, educational and administration groups. The implementation of fuzzy of this paper uses triangular numbers.

\subsection{Fuzzy numbers}

Zadeh is believed to be the first who introduced fuzzy Logic in 1965. Triangular and trapezoid fuzzy numbers are considered as a special form of Fuzzy LR numbers and they are utilized, which are special forms of fuzzy sets.

\subsubsection{Fuzzy sets and determining membership degrees}

In each fuzzy set, a degree of membership is determined for each member changes from zero to one. The degree of membership is based on either mathematical functions, or expert opinion.

A fuzzy set if displayed as below:

$\mu_{A}(x \mid: x \rightarrow[\circ, 1]$,

$\mathrm{A}\left\{\mathrm{x}, \mu_{\mathrm{A}}(\mathrm{x}): \mathrm{x} \in \mathrm{X}^{2}\right)$.

The membership function of triangular fuzzy numbers is defines as follows,

$\mu_{x}=\left\{\begin{array}{cc}\frac{x-a}{b-a} & a \leq x \leq b \\ \frac{c-x}{c-b} & b \leq x \leq c \\ 0 & \text { otherwise }\end{array}\right.$

\subsubsection{Mathematical operation on fuzzy numbers}

Let $\tilde{N}$ and $\tilde{M}$ be two triangular numbers and $\lambda$ be a positive real number, then, the following arithmetic operations are defined.

$$
\begin{aligned}
& \tilde{N}+\tilde{M}=\left(a_{1}+a_{r}, b_{1}+b_{r}, c_{1}+c_{r}\right), \\
& \tilde{N}-\tilde{M}=\left(a_{1}-a_{r}, b_{1}-b_{r}, c_{1}-c_{r}\right), \\
& \tilde{N} \times \tilde{M}=\left(a_{1} \times a_{r}, b_{1} \times b_{r}, c_{1} \times c_{r}\right), \\
& \lambda+\tilde{M}=\left(\lambda \times a_{r}, \lambda \times b_{r}, \lambda \times c_{r}\right), \\
& \tilde{N}^{\lambda}=\left(a_{1}{ }^{\lambda}, b_{1}{ }^{\lambda}, c_{1}{ }^{\lambda}\right) .
\end{aligned}
$$

\subsection{Analytical network process}


Analytic hierarchy process (AHP) is one of the most popular approaches to handle problems with multiple criteria. There are different assumptions when AHP is applied to make decisions, such as, the independence between higher-level elements and lower-level elements, the independence of the elements within a level, and the hierarchy structure of the decision problem (Saaty 1994, Saaty \& Zoffer 2011). Nevertheless, an important limitation of AHP is associated with the assumption of independency among various criteria of decision-making. Analytic network process (ANP), on the other hand, uses interdependencies among the decision attributes and permits us a more systematic analysis. Besides, the interactions of decision attributes within the same level and the feedbacks between two various levels are critical issues, which ought to be taken into account during the decision making procedure. Therefore, the AHP method does not work properly when solving such decision problems (Saaty, 1996). ANP, as a modified and complementary technique of the AHP, was introduced and further developed by Saaty (1996, 1999, 2001, 2003, 2004, 2005, 2006, and 2008). In contrast to AHP, ANP provides a more generalized model in decision-making without making additional assumptions about the independency of the higher-level elements from lower-level elements and different elements within a level.

\section{Step 1: Model construction and problem structuring}

The problem needs to be stated clearly and decomposed into rational system like network. The structure can be reached by the opinion of decision makers through brainstorming or other appropriate techniques

\section{Step 2: Pairwise comparisons matrices and priority vectors}

In ANP, similar to AHP, decision elements at each component are compared pairwise with respect to their importance towards their control criterion, and the components themselves are also compared pairwise with respect to their contribution to the goal. Decision makers are requested to respond to a series of pairwise comparisons where two elements or two components at a time are compared in terms of how they contribute to their particular upper level criterion (Sarkis, 2003). The relative values are determined with Saaty's 1-9 scale (Table 1), where a score of 1 indicates equal importance between the two elements and a score 9 represents the extreme importance of one element (row component in the matrix) compared with the other one (Sarkis, 2003).

\section{Table 1}

Saaty's 1-9 scales for AHP

\begin{tabular}{lllllll}
\hline Definition & $\begin{array}{l}\text { Equal } \\
\text { importance }\end{array}$ & $\begin{array}{l}\text { Moderate } \\
\text { importance }\end{array}$ & $\begin{array}{l}\text { Strong } \\
\text { importance }\end{array}$ & $\begin{array}{l}\text { Very strong } \\
\text { importance }\end{array}$ & $\begin{array}{l}\text { Absolute } \\
\text { importance }\end{array}$ & $\begin{array}{l}\text { Intermediate } \\
\text { importance }\end{array}$ \\
\hline $\begin{array}{l}\text { Intensity of } \\
\text { importance }\end{array}$ & 1 & 3 & 5 & 7 & 9 & $2,4,6,8$ \\
\hline
\end{tabular}

Like AHP, pairwise comparison in ANP is accomplished in the framework of a matrix, and a local priority vector derived as an estimate of relative importance associated with the elements (or components) being compared by solving the following equation:

$W_{n}=\left[\begin{array}{ccc}0 & 0 & 0 \\ w_{21} & w_{22} & 0 \\ 0 & w_{32} & I\end{array}\right] A \times w=\lambda_{\max } \times w$

where $A$ is the matrix of pairwise comparison, $w$ is the eigenvector, $\lambda_{\max }$ is the largest Eigen value of $A$. 
The super matrix concept looks like the Markov chain process (Saaty, 2005). To calculate global priorities in a system with interdependent effects, the local priority vectors are considered in the appropriate columns of a matrix. As a result, a super matrix is actually a decomposed matrix, where each matrix segment indicates a relationship between two nodes in a system (Sarkis, 2003).

Let $C_{k}, \mathrm{k}=1,2$, $\mathrm{n}$ be the components of a decision systems, and each component $k$ has $m_{k}$ elements, denoted by $e_{k 1}, e_{k 2}, \ldots, e_{k m k}$. The comparison matrix has the following form,

$$
W_{h}=\left[\begin{array}{ccc}
0 & 0 & 0 \\
W_{21} & 0 & 0 \\
0 & W_{32} & I
\end{array}\right],
$$

where $w_{21}$ represents a vector, which shows the effect of the goal on the criteria, $w_{32}$ is a matrix that represents the effect of criteria on each of the alternatives, $I$ is the identity matrix, and entries of zeroes corresponding to those elements that have no impact.

\section{Solving Impulse Buying Model}

For solving this model, we reform our model in a simple figure to put in software. We gathered factors' weights from experts by using special ANP questionnaires. Then we put these gathered weights in the Supper decision software.

\section{Case study}

In this paper, we have used ANP method for ranking different factors influencing employees' counterproductive behaviors. The study prepared a questionnaire and accomplished the survey in different stages. During the first stage, we have performed a brain storming survey to determine important factors and after having different sessions and gathering all insights, we have asked 40 decision makers who worked for Islamic Azad University, North branch, in city of Tehran, Iran to make a pairwise comparison on each pair of alternatives. Table 2 shows details of our findings,

Table 2

The summary of scores given to different factors

\begin{tabular}{|c|c|c|c|c|}
\hline Factor & Sub-factor & Sub-Mean & Average & \\
\hline \multirow[b]{2}{*}{ Hypothyroidism } & Dodging duties & 3.74 & \multirow[t]{2}{*}{3.53} & \multirow[t]{2}{*}{ Desirable } \\
\hline & Avoiding work with others & 3.33 & & \\
\hline \multirow{4}{*}{ Vandalizing } & Persuading other workers to work less & 3.25 & \multirow{4}{*}{2.94} & \multirow{4}{*}{ Undesirable } \\
\hline & Keeping the work environment untidy & 2.35 & & \\
\hline & Vandalizing computer hardware and software & 3.5 & & \\
\hline & Vandalizing other equipment & 2.66 & & \\
\hline \multirow{4}{*}{ Ruin the mood } & Harming colleagues’ emotional feeling & 3.03 & \multirow{4}{*}{3.19} & \multirow{4}{*}{ Border line } \\
\hline & Applying course language against colleagues & 3.34 & & \\
\hline & Disputes and conflicts with colleagues & 3.1 & & \\
\hline & Blackguard and disputes with clients & 3.29 & & \\
\hline \multirow[t]{2}{*}{ Other factors } & Falsifying records & 2.53 & \multirow[t]{2}{*}{2.95} & \multirow[t]{2}{*}{ Undesirable } \\
\hline & Abuse of referees & 3.38 & & \\
\hline
\end{tabular}

As we can observe from the results of Table 2, the employees of this organization are blamed mostly in terms of vandalizing and other factors while their behavior tend to ruin the existing mood in this firm. Based on these results, we have asked decision makers on how to improve the efficiency of organization and using ANP method ranked all factors. Table 3 shows details of our survey.

\section{Table 3}

The results of our survey on ranking different factors on improving productivity 


\begin{tabular}{lc}
\hline Item & Weight \\
\hline Management Accountability & 0.3242 \\
Coherence and unity with no dispersion of the employee's duties & 0.3410 \\
Variety of tasks (not boring, repetitive tasks) & 0.3347 \\
Systematic job rotation & 0.3364 \\
Clear duties & 0.3331 \\
Complex duties & 0.3305 \\
Overlapping duties & 0.2489 \\
Repeating tasks due to lack of proper use of relevant records & 0.2522 \\
Correct design of communication in job & 0.2545 \\
Frequent relocation job & 0.2444 \\
Balance workload & 0.2483 \\
The ability of analyzing issues & 0.2438 \\
\hline
\end{tabular}

\section{Discussion and conclusion}

Based on the results of our investigation, we understand that the employees of this organization could be blamed mostly in terms of vandalizing and other factors while their behaviors tend to ruin the existing mood in this firm. In order to improve the performance of the employees, it appears that having coherence and unity with no dispersion of the employee's duties is number one priority in our survey followed by systematic job rotation and having diversity on task responsibilities. In addition, when there is a good definition on task duties, employee may show their talents, more efficiently. The employees believe when they face with complex duties, they may have more difficulty on handling the issues but, at the same time, the nature of work will not be boring. Therefore, they may show their creativity and innovation to solve various problems and we may expect more efficiency.

\section{Acknowledgement}

The authors would like to thank the employees of Islamic Azad University, North Branch, for cordially participating in this survey. We are also delighted for constructive comments on earlier version of this paper.

\section{References}

Allameh, S. M., Momeni, Z., \& Esfahani, Z. S. (2011). An assessment of the effect of information communication technology on human resource productivity of Mobarekeh steel complex in Isfahan (IRAN). Procedia Computer Science, 3, 1321-1326.

Bloom, N., \& Reenen, J. V. (2011). Human resource management and productivity. Handbook of Labor Economics, 4, 1697-1767.

Divkolaii, M. (2014). An investigation on factors influencing on human resources productivity. Management Science Letters, 4(5), 883-886.

Oleyaei-Motlagh, S \& Bonyadi-Naeini, A. (2014). Identifying the role of human resource management in increasing performance and implementation of six sigma projects using fuzzy cognitive maps. Uncertain Supply Chain Management, 2(3), 179-190.

Saaty, T.L. (1994). Fundamentals of the Analytic Hierarchy Process. RWS Publications, 4922 Ellsworth Ave., Pittsburgh, Pennsylvania.

Saaty, T.L. (1996). Decision Making with Dependence and Feedback: The Analytic Network Process. Pittsburgh, Pennsylvania: RWS Publications. ISBN 0-9620317- 9-8.

Saaty, T.L. (1999). Fundamentals of the analytic network process. ISAHP 1999, Kobe, Japan, August 12-14.

Saaty, T.L. (2001). Decision Making with the Analytic Network Process (ANP) and Its "Super Decisions" Software: The National Missile Defense (NMD) Example. ISAHP 2001 Proceedings, Bern, Switzerland, August, 2-4. 
Saaty, T.L. (2003). Theory of the Analytic Hierarchy and Analytic network process - Examples Part 2.2. The International Journal of Systems Research and Information Technologies, 2.

Saaty, R. W. (2003). Decision making in complex environment: The analytic hierarchy process (AHP) for decision making and the analytic network process (ANP) for decision making with dependence and feedback. Pittsburgh: Super Decisions.

Saaty, T.L. (2004).Fundamentals of the Analytic Network Process: Dependence and Feedback in Decision-Making with a Single Network. Journal of Systems Science and Systems Engineering, published at Tsinghua University, Beijing, 13(2), 129-157.

Saaty, T.L. (2005). Theory and Applications of the Analytic Network Process: Decision Making with Benefits, Opportunities, Costs and Risks. Pittsburgh, Pennsylvania: RWS Publications. ISBN 1888603-06-2.

Saaty, T.L. (2006). Rank from comparisons and from ratings in the analytic hierarchy/ network processes. European Journal of Operational Research, 168, 557-570.

Saaty, T.L. (2008).The Analytic Network Process. Iranian Journal of Operations Research, 1(1), 127.

Saaty, T. L., Zoffer, H.J., (2011) Negotiating the Israeli-Palestinian Controversy from A New Perspective, DOI: 10.1142/S021962201100421X, International Journal of Information Technology \& Decision Making, 10(1), Jan 2011.

Sarkis, J. (2003). Quantitative models for performance measurement systems alternate considerations. International Journal of Production Economics. 86 (1), 81-90.

Zheng, S., \& Sun, Y. (2011). The analysis of human factors on grassland productivity in Western Songnen Plain. Procedia Environmental Sciences, 10(B), 1302-1307. 